\title{
Mudas de Luehea divaricata produzidas com biossólidos de duas estações de tratamento de esgoto
}

\author{
Thasso José Silva e Sousa ${ }^{1}$ Jorge Markhlouta Alonso ${ }^{1}$ Paulo Sérgio dos Santos Leles ${ }^{1}$ Elton Luis da Silva \\ Abel $^{1}$ Juçara Garcia Ribeiro ${ }^{1}$ João Elves da Silva Santana ${ }^{1}$
}

${ }^{1}$ Universidade Federal Rural do Rio de Janeiro, Instituto de Florestas, BR 465, km7, Seropédica-RJ, CEP 23890-000

*Author for correspondence: pleles@ ufrrj.br

Received: July 2018 / Accepted: May 2019/ Published: June 2019

\section{Resumo}

Avaliou-se o potencial de biossólidos procedentes de duas estações de tratamento de esgoto (ETE) para produção de mudas de Luehea divaricata, em comparação com um substrato comercial. Os tratamentos foram os biossólidos provenientes da ETE Sarapuí, localizada no município de Belford Roxo e da ETE do bairro Ilha do Governador, na cidade do Rio de Janeiro, além do substrato comercial formado por casca de pinus compostada e vermiculita. As mudas foram produzidas em tubetes $280 \mathrm{~cm}^{3}$. Utilizou-se o delineamento inteiramente casualizado com quatro repetições, de seis mudas. Ao final do experimento, 105 dias após a repicagem, mensurou-se altura da parte aérea, diâmetro do coleto, área foliar, massa de matéria seca da parte aérea (MSPA) e de raízes (MSR). Foram calculadas a massa seca total, relação MSR / MSPA e índice de qualidade de Dickson. Constatou-se que, para a maioria dos parâmetros avaliados, os biossólidos de ambas as ETEs produziram mudas de Luehea divaricata com crescimento superior às produzidas com substrato comercial. Conclui-se que ambos os biossólidos são adequados para a produção de mudas da espécie estudada em tubetes de $280 \mathrm{~cm}^{3}$, sendo preferível utilizar biossólido da ETE Sarapuí.

Palavras-chave: Açoita-cavalo, Lodo de esgoto, Substrato e Viveiros florestais.

\begin{abstract}
This paper evaluated the potential of biosolids from two wastewater treatment plants (WWTP) as substrate for Luehea divaricata seedlings in comparison with a commercial substrate. The treatments were biosolids from WWTP Sarapuí, located in the Belford Roxo municipality, biosolids from the WWTP Ilha do Governador, located in Rio de Janeiro municipality and a commercial substrate composed of pine bark and vermiculite. The seedlings were produced in $280 \mathrm{~cm}^{3}$ plastic tubes and the experiment was conducted using completely randomized design, with four replications of six seedlings per treatment. At the end of the experiment, 105 day after transplanting, the seedlings were measured evaluating the shoot height, root collar diameter, foliar surface, shoot and root dry weight. These parameters were used to calculate the total dry weight, root / shoot ratio and Dickson quality index. It was observed that biosolids from both WWTP had superior results than the commercial substrate for most parameters evaluated in the production of Luehea divaricata seedlings. It is possible to conclude that both biosolids are suitable to produce seedlings of the studied species in 280 $\mathrm{cm}^{3}$ plastic tubes, being preferable to use biosolids from WWTP Sarapuí.
\end{abstract}

Keywords: Azota Caballo, sewage sludge, substrate and forest nurseries.

\section{Introdução}

A crescente conscientização ambiental da sociedade tem demandado do poder público e de empresas privadas maiores investimentos na conservação de recursos naturais, bem como a melhoria dos serviços de saneamento básico. As estações de tratamento de esgotos (ETE), segundo SNIS (2016), possuem importante papel na prestação de serviços ambientais à sociedade, coletando e tratando diariamente milhões de litros de efluentes domiciliares, evitando que consideráveis cargas de poluentes cheguem aos mananciais hídricos.

De maneira simplificada, segundo Pereira et al. (2013) o tratamento de esgoto consiste em um conjunto de processos físicos, químicos e biológicos que resultam na remoção da matéria orgânica e dos sólidos sedimentáveis. O resíduo sólido resultante desse processo é o lodo de esgoto, formado pela matéria particulada orgânica e inorgânica decantada durante o tratamento primário do esgoto (lodo primário) e microrganismos excedentes produzidos durante o processo de ativação biológica do esgoto no tratamento - lodo secundário (Christodoulou e Stamatelatou, 2016)

Após estabilizado visando sua reutilização, o lodo de esgoto passa a ser denominado biossólido. Trabalhos mostram que este material é rico em nutrientes e matéria orgânica (Abreu et al. 2017a) e para sua utilização em atividades agropecuárias é necessário atender aos parâmetros descritos na resolução CONAM A n 375/2006, visando evitar riscos à saúde pública e ao meio ambiente (Brasil 2006). De acordo com Kominko et al. (2017), devido à origem do esgoto, das técnicas empregadas para o tratamento (tratamento primário e ou secundário), dentre outros fatores, biossólidos provenientes de diferentes ETEs tendem a possuir diferentes atributos químicos e físicos.

Uma alternativa para reciclagem do biossólido é a sua utilização como componente de substrato para produção de mudas florestais. Tal emprego tem se mostrado viável tanto do ponto de vista técnico como do ambiental, produzindo mudas de qualidade, contribuindo para formação de povoamentos florestais e promovendo destinação mais sustentável quando comparada à disposição em aterros sanitários (Abreu et al. 2017a). Estudos realizados indicam que biossólido pode ser usado como componente de substrato para produção de mudas de espécies arbóreas da Mata Atlântica (Scheer et al. 2012; Abreu et al. 2017b; Cabreira et al. 2017a; Alonso et al. 2018; Lima Filho et al. 2019). Em trabalhos de Cabreira et al. (2017b), Abreu et al. (2018) e Alonso et al. (2018) mostrou viável a utilização de biossólido como único material do substrato. $\mathrm{O}$ uso do biossólido também reduz ou elimina os gastos com substratos comerciais (Nobrega et al. 2017), podendo aumentar o lucro dos produtores de mudas. 
Mais estudos são necessários devido a diversidade de espécies arbóreas usadas em trabalhos de restauração da Mata Atlântica e também devido as variações existentes nos biossólidos de lodo de esgoto. Biossólidos procedentes de diferentes estações normalmente apresentam características químicas e físicas diferentes, dependendo dos hábitos alimentares dos moradores de onde é coletado o esgoto e o tratamento do esgoto até o biossólido.

Segundo Carvalho (2008), entre as espécies com potencial de uso em reflorestamentos mistos com fins de restauração florestal, encontra-se Luehea divaricata Mart. \& Zucc, conhecida popularmente como açoita-cavalo, pertencente à família Malvaceae. Este autor menciona que a espécie apresenta porte arbóreo, é heliófita e de caráter decíduo, podendo atingir até $30 \mathrm{~m}$ de altura. Possui potencial ornamental, em virtude da beleza de suas flores e possui madeira moderadamente pesada e de fácil trabalhabilidade, sendo própria para confecção de móveis e na construção civil.

Este trabalho teve como objetivo avaliar o potencial do biossólido de duas estações de tratamento de esgoto na produção de mudas de Luehea divaricata Mart. \& Zucc. em comparação com um substrato comercial.

\section{Material e métodos}

O experimento foi conduzido em viveiro florestal, localizado no município de Seropédica - RJ, no período de agosto a dezembro de 2016. O clima local, segundo a classificação de Köppen, é do tipo Aw, que significa tropical com chuvas de verão. De acordo com os dados da estação meteorológica da Embrapa Agrobiologia, localizada próxima ao experimento, no período da semeadura até última avaliação das mudas, a média da temperatura máxima diária foi de $29,3{ }^{\circ} \mathrm{C}$ (variando de $19,8^{\circ} \mathrm{C}$ a $39,0{ }^{\circ} \mathrm{C}$ ) e temperatura mínima diária foi de 19,0 ${ }^{\circ} \mathrm{C}$ (variando de $11,0{ }^{\circ} \mathrm{C}$ a $24,6{ }^{\circ} \mathrm{C}$ ). A umidade relativa média diária desse período foi de $73,5 \%$.

Os biossólidos utilizados foram cedidos pela Companhia Estadual de Águas e Esgotos do Rio de Janeiro (CEDAE), sendo oriundos de duas estações de tratamento de esgoto. A ETE Ilha do Governador se localiza no SubBairro Tauá, Bairro da Ilha do Governador, no município do Rio de Janeiro $\left(22^{\circ} 47^{\prime} 44^{\prime \prime} \mathrm{S}\right.$ e $\left.43^{\circ} 11^{\prime} 15^{\prime \prime} \mathrm{W}\right)$. Essa ETE trata todo o esgoto da Ilha do Governador, região prioritariamente residencial da cidade. $\mathrm{O}$ tratamento de esgoto é realizado a nível primário e secundário pelo sistema de lodos ativados. O lodo proveniente do processo de tratamento primário é misturado ao do tratamento secundário para depois passar por adensamento em centrífuga. Após o adensamento, o material é disposto em leitos de secagem semipermeáveis ao ar livre, onde permanece em média 90 dias.

A ETE Sarapuí se situa no Bairro Jardim Glaucia,

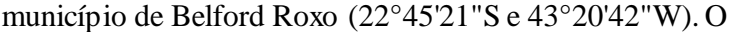
esgoto tratado nessa ETE é de origem residencial e comercial, proveniente dos municípios de Duque de Caxias, Nilópolis, São João de Meriti e Nova Iguaçu, região metropolitana do estado do Rio de Janeiro. Nessa ETE é realizado tratamento primário quimicamente assistido e secundário pelo sistema de lodos ativados. $\mathrm{O}$ lodo do tratamento secundário é adensado e misturado ao do tratamento primário para passagem por centrífuga de desaguamento. Após esse processo, o material é levado ao secador térmico até atingir teor de umidade abaixo de $10 \%$.

Segundo indicações de rótulo, o substrato comercial utilizado é formado, em volume, por $80 \%$ de casca de pinus decomposta e $20 \%$ de vermiculita, além de corretivo de acidez e macronutrientes. Aparentemente, apresenta-se com granulometria uniforme e bem compostado.

Conforme determina a Resolução CONAMA n ${ }^{\circ}$ 375/2006 (Brasil, 2006) foi realizada a caracterização química dos dois biossólidos, sendo avaliados os teores de macronutrientes, alumínio, matéria orgânica, teor de metais pesados e calculada a relação carbono / nitrogênio. O método aplicado foi o EPA 3050, com digestão ácida $\left(\mathrm{HNO}_{3}+\mathrm{H}_{2} \mathrm{O}_{2}\right)$ em blocos digestores em temperatura de $95{ }^{\circ} \mathrm{C}$. A determinação de $\mathrm{K}$ foi realizada por fotometria de chama e os demais elementos por espectrometria de emissão atômica por plasma acoplado indutivamente (ICP-OES). Os dados de metais pesados da Tabela 1 evidenciam que ambos os biossólidos podem ser utilizados para atividades agropecuárias. Os teores de $\mathrm{C}$ e $\mathrm{N}$ foram determinados pelo método de combustão a seco, em um auto-analisador CHN-600. A matéria orgânica foi calculada a partir do teor de carbono total presente em cada amostra, usando o fator de conversão de "van Bemmelen" de 1,724 .

Tabela 1: Teores totais de macronutrientes $\left(\mathrm{g} \mathrm{kg}^{-1}\right)$, alumínio, matéria orgânica, relação carbono / nitrogênio e metais pesados $\left(\mathrm{mg} \mathrm{kg}^{-1}\right)$ de biossólidos provenientes de duas estações de tratamento de esgoto e em substrato comercial utilizados para produção de mudas de Luehea divaricata

\begin{tabular}{|c|c|c|c|}
\hline Analisado & Subst. Comercial & Biossólido ETE Sarapuí & Biossólido ETE Illha Governador \\
\hline Nitrogênio $\left(\mathrm{g} \mathrm{kg}^{-1}\right)$ & 7,90 & 19,39 & 18,33 \\
\hline Fósforo $\left(\mathrm{g} \mathrm{kg}^{-1}\right)$ & 2,19 & 16,38 & 7,62 \\
\hline Potássio $\left(\mathrm{g} \mathrm{kg}^{-1}\right)$ & 2,13 & 2,36 & 1,26 \\
\hline Cálcio $\left(\mathrm{g} \mathrm{kg}^{-1}\right)$ & 3,73 & 16,67 & 12,51 \\
\hline Magnésio $\left(\mathrm{g} \mathrm{kg}^{-1}\right)$ & 3,52 & 3,56 & 1,90 \\
\hline Alumínio $\left(\mathrm{g} \mathrm{kg}^{-1}\right)$ & 222,85 & 119,52 & 150,45 \\
\hline Matéria Orgânica (\%) & 38 & 21 & 26 \\
\hline Relaç̃o C/N & 28 & 6 & 8 \\
\hline Arsênio $\left(\mathrm{mg} \mathrm{kg}^{-1}\right) 41^{*}$ & 0,2 & não detectado & não detectado \\
\hline Bário (mg kg-1) $1300^{*}$ & 47,6 & 503,6 & 178,1 \\
\hline Cádmio $\left(\mathrm{mg} \mathrm{kg}^{-1}\right) 39 *$ & 0,2 & 1,9 & 1,1 \\
\hline Cromo $\left(\mathrm{mg} \mathrm{kg}^{-1}\right) 1000^{*}$ & 24,2 & 121,2 & 33,7 \\
\hline Cobre $\left(\mathrm{mg} \mathrm{kg}^{-1}\right) 1500^{*}$ & 12,5 & 127,0 & 212,0 \\
\hline Níquel $\left(\mathrm{mg} \mathrm{kg}^{-1}\right) 420^{*}$ & 13,3 & 22,8 & 17,3 \\
\hline Chumbo $\left(\mathrm{mg} \mathrm{kg}^{-1}\right) 300^{*}$ & 6,3 & 100,8 & 141,8 \\
\hline Selênio $\left(\mathrm{mg} \mathrm{kg}^{-1}\right) 100^{*}$ & não detectado & não detectado & não detectado \\
\hline Zinco $\left(\mathrm{mg} \mathrm{kg}^{-1}\right) 2800^{*}$ & 28,1 & 837,6 & 822,6 \\
\hline
\end{tabular}

*valores máximos permitidos pela Resolução CONAMA $\mathrm{n}^{\mathrm{o}} 375 / 2006$ (mg kg${ }^{-1}$, base seca).

Dados médios de características físicas dos substratos antes do enchimento dos recipientes encontramse na Tabela 2. $\mathrm{O} \mathrm{pH}$ e a condutividade elétrica (CE) foram determinados usando $5 \mathrm{~g}$ de cada amostra diluída em 50 $\mathrm{mL}$ de água deionizada, agitado por 30 minutos e em seguida medidos em medidor de $\mathrm{pH}$ e condutivímetro de bancada. As análises de densidade, porosidade e capacidade de retenção de água seguiram as orientações descritas em análises de substrato de Firmino (2014).

Tabela 2: Valores médios de $\mathrm{pH}$, condutividade elétrica (CE), densidade úmida (DU), densidade aparente (DA), densidade de partículas (DP), macroporosidade (Macro), microporosidade (Micro), porosidade total (PT) e capacidade de retenção de água (CRA) de biossólidos de duas estações de tratamento de esgoto e de substrato comercial utilizados na produção de mudas de Luehea divaricata 


\begin{tabular}{|c|c|c|c|c|c|c|c|c|c|c|}
\hline \multirow{2}{*}{ Substrato } & $\mathrm{pH}$ & $\mathrm{CE}$ & DU & DA & DP & Macr & icro & PT & \multirow{2}{*}{\multicolumn{2}{|c|}{$\begin{array}{l}\text { CRA }(10 \mathrm{~cm}) \text { CRA }(50 \mathrm{~cm}) \\
-10 \mathrm{~mL} 50 \mathrm{~cm}^{3}\end{array}$}} \\
\hline & & $\mathrm{dS} / \mathrm{m}$ & $\mathrm{kgm}^{3}$ & & & 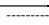 & $-\%-$ & 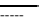 & & \\
\hline Comercial & 6,1 & 0,65 & 520 & 0,23 & 519,6 & 43,5 & 38,7 & 82,2 & 31,9 & 19,4 \\
\hline ossólido E & 7,6 & 2,44 & 728 & 0,68 & 727,8 & 28,8 & 34,3 & 63,0 & 24,0 & 17,1 \\
\hline ossolido ETE Iha do Gr & 5,7 & 2,66 & 532 & 0,50 & 531,9 & 35,5 & 41,5 & 77,0 & 33,1 & 20,8 \\
\hline
\end{tabular}

Os tratamentos foram constituídos por T1 - substrato comercial à base de casca de pinus (testemunha), T2 biossólido proveniente da ETE Sarapuí e T3 - biossólido da ETE Ilha do Governador. Utilizou-se delineamento inteiramente casualizado com 4 repetições, sendo cada repetição composta por 6 mudas, totalizando 24 mudas de cada tratamento.

Foram utilizados como recipiente tubetes de polipropileno com capacidade volumétrica de $280 \mathrm{~cm}^{3}$, os quais foram preenchidos manualmente com o substrato correspondente a cada tratamento e dispostos em bandejas suspensas. Em seguida, procedeu-se a repicagem das plântulas de açoita-cavalo, que foram germinadas em sementeiras evitando perdas no experimento por eventual baixa taxa de germinação. Nos primeiros 20 dias após a repicagem foi mantido sobre as plântulas sombrite de cor preta com passagem de $50 \%$ da luminosidade, como forma de proteção da incidência solar direta. Não foi realizada fertilização complementar nem de base, nem de cobertura em nenhum dos tratamentos. Aos 45 dias após repicagem, foi feito reespaçamento das mudas nas bandejas para ocupação de $50 \%$ das células, a fim de diminuir a competição por luz. Ao longo do experimento a irrigação foi realizada por microaspersores, de acordo com as condições ambientais e a experiência do viveirista. Sempre que necessário, foram realizadas limpezas das mudas, sendo retiradas plantas espontâneas presentes no substrato.

Aos 60 dias após a repicagem iniciaram-se as medições de altura da parte aérea $(\mathrm{H})$, que se repetiram em intervalos de 15 dias, até a fase de expedição das mudas para o campo. Aos 105 dias após a repicagem o experimento foi finalizado, tendo em vista que as mudas de dois tratamentos atingiram porte para expedição, considerado como altura da parte aérea maior que $25 \mathrm{~cm}$. Nessa ocasião, além da altura da parte aérea, também foi mensurado o diâmetro do coleto (D). Após o processamento dos dados, foram selecionadas quatro mudas médias de cada tratamento (com base na altura) para determinação dos parâmetros área foliar (AF) e massa de matéria seca da parte aérea (MSPA) e de raízes (MSR). Para isso, essas mudas foram separadas em parte aérea (folhas mais caule) e raízes. A área foliar foi mensurada com auxílio de medidor LICOR-3600. O sistema radicular foi lavado cuidadosamente em água corrente e colocado para secar a sombra. A parte aérea e o sistema radicular, de cada muda foram acondicionados em sacos de papel identificados e em seguida levados para uma estufa de circulação de ar forçada, onde permaneceram a $65^{\circ} \mathrm{C}$, durante 72 horas.

A partir dos dados obtidos, foram calculados a massa de matéria seca total(MST), relação massa de matéria seca da parte aérea / massa matéria seca de raízes (MSPA/MSR). Com essas relações, calculou-se o índice de qualidade de Dickson (IQD) (Dickson et al. 1960), por meio da equação: $I Q D=\left(\frac{M S T}{\frac{H}{D}+\frac{M S P A}{M S R}}\right)$

Em que: $\mathrm{H}=$ altura parte aérea e $\mathrm{D}=$ diâmetro do coleto das mudas.

Para cada tratamento foi ajustado um modelo de regressão relacionando o tempo de 60 a 105 dias após a repicagem com as alturas das mudas produzidas, sendo os coeficientes das equações testados pelo test $t$ de student.

Os dados das variáveis mensuradas da última medição, foram submetidos à análise de variância $(p>0,95)$ e quando detectadas diferenças significativas, as médias dos tratamentos foram comparadas pelo teste de Tukey a $95 \%$ de probabilidade.

\section{Resultados}

Constata-se pela Figura 1, crescimento linear em altura das mudas de Luehea divaricata produzidas nos três substratos em função da idade (tempo após a repicagem). A reta de crescimento das mudas produzidas com biossólido da ETE Sarapui teve maior inclinação entre as quatro épocas avaliadas e a do substrato comercial a menor inclinação, indicando menor resposta de crescimento em altura das mudas ao longo do tempo. Observa-se ainda, que no substrato comercial a equação linear teve o menor grau de ajuste $\left(\mathrm{R}^{2}\right)$, indicando alturas mais heterogêneas entre as mudas desse tratamento. 


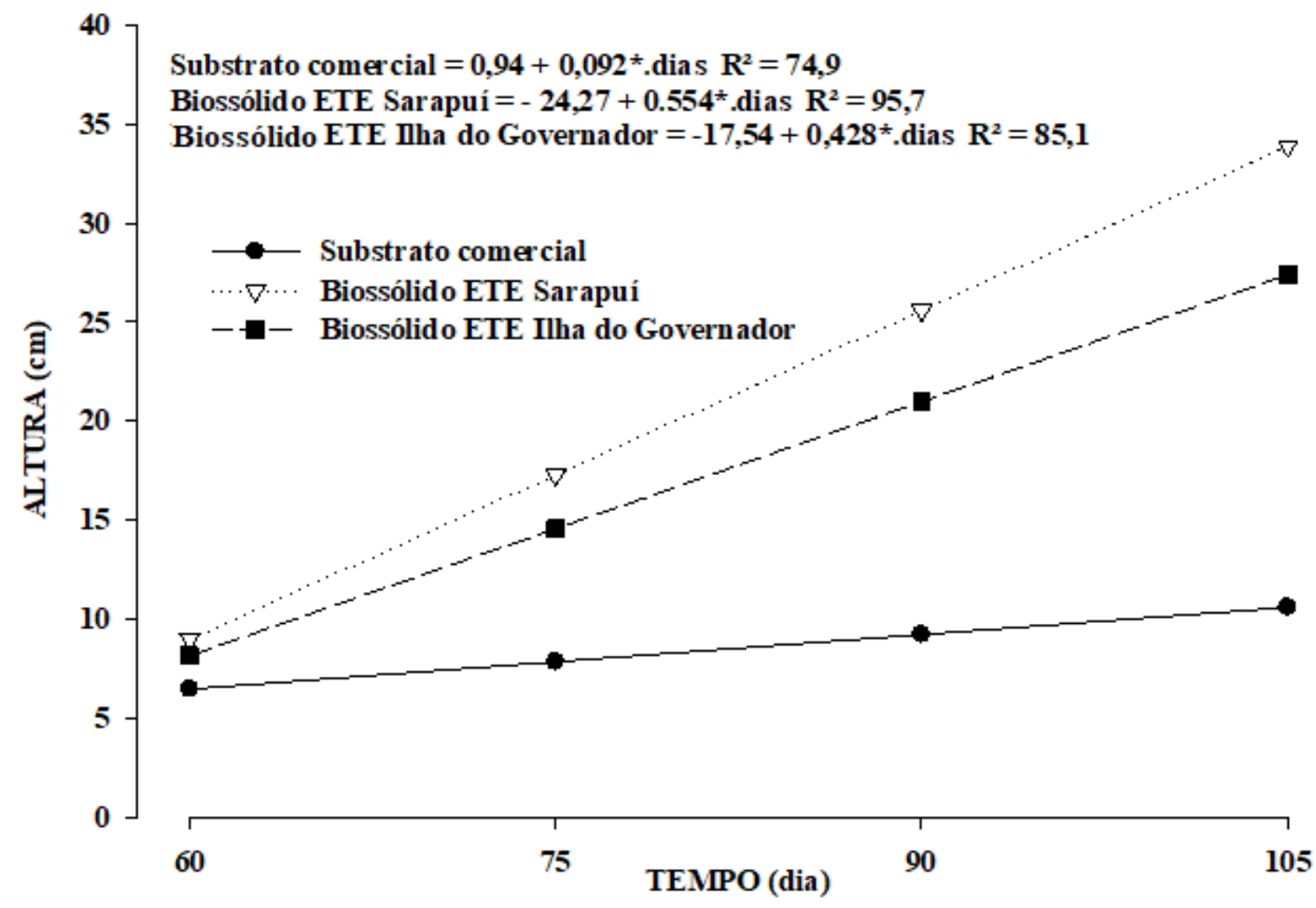

Figura 1: Crescimento em altura de mudas de Luehea divaricata, dos 60 aos 105 dias após a repicagem em três substratos. *significativo ao nível de 5\% de probabilidade pelo teste $t$ de student.

De acordo com o teste F, foram encontradas diferenças entre os parâmetros de crescimento das mudas produzidas nos três substratos $(\mathrm{p} \geq 0,95)$. Observa-se pela Tabela 3 , para todos os parâmetros avaliados excluindo-se a relação entre matérias secas, que as mudas produzidas com o biossólido de ambas as ETEs obtiveram valores maiores que as produzidas com substrato comercial.

Tabela 3: Valores médios de altura da parte aérea $(\mathrm{H})$, diâmetro do coleto (D), área foliar (AF), matéria seca de parte aérea (MSPA), de raízes (MSR) e total (MST), relação parte aérea / raiz (MSPA/MSR) e índice de qualidade de Dickson (IQD) de mudas de Luehea divaricata produzida em três substratos, aos 105 dias após a repicagem

\begin{tabular}{|c|c|c|c|c|c|c|c|c|}
\hline Treatumento & 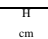 & $\underset{\substack{\mathrm{m} \\
\mathrm{m}}}{\mathrm{D}}$ & & MSPA & 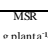 & MST & MSPAMSR & 1012 \\
\hline Biosostin & $33.5 \mathrm{a}$ & $4,8 \mathrm{a}$ & 8 & & $0.68 \mathrm{a}$ & 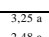 & & \\
\hline & $\begin{array}{l}\text {.0.8. } \\
10.2 \mathrm{c}\end{array}$ & $\begin{array}{l}4_{0,0 \mathrm{~b}} \\
1.0 \mathrm{c}\end{array}$ & $\begin{array}{l}224 \mathrm{a} \\
14 \mathrm{~b}\end{array}$ & $\begin{array}{l}2.27 \mathrm{a} \\
0.34 \mathrm{~b}\end{array}$ & $\begin{array}{l}0.21 \mathrm{~b} \\
0.05 \mathrm{c}\end{array}$ & $\begin{array}{l}2.48 \mathrm{a} \\
0.39 \mathrm{~b}\end{array}$ & $\begin{array}{l}7,019 \mathrm{a} \\
7,15 \mathrm{~b}\end{array}$ & $\begin{array}{l}0.14 \mathrm{~b} \\
0.03 \mathrm{c}\end{array}$ \\
\hline
\end{tabular}

Médias seguidas da mesma letra, na coluna, não diferem entre si, pelo teste de Tukey $(\mathrm{p} \geq 0,95)$.

Para altura e diâmetro de coleto o substrato da ETE Sarapuí proporcionou crescimento significativamente superior aos demais. Já o substrato comercial apresentou valores médios inferiores.

Em relação à área foliar e massa de matéria seca da parte aérea (MSPA) não houve diferenças significativas entre as mudas oriundas dos dois biossólidos, as quais foram superiores às do substrato comercial.
Quanto à produção de raízes, as mudas produzidas com biossólido da ETE Sarapuí foram superiores às demais, já o substrato comercial teve resultado inferior.

Os valores médios da relação de massa de matéria seca da parte aérea / raízes (MSPA / MSR) variaram entre 3,85 a 11,11. O índice de qualidade de Dickson (IQD) indica que as mudas produzidas com biossólido da ETE Sarapuí foram as de melhor qualidade, enquanto aquelas produzidas com substrato comercial apresentaram pior qualidade.

\section{Discussão}

O uso do biossólido de ambas ETEs acelerou o crescimento das mudas de Luehea divaricata, sendo que o biossólido da ETE Sarapuí proporcionou maior crescimento e inclinação da reta do que o da ETE Ilha (Figura 1). Tal fato ocorreu devido ao maior teor de nutrientes no biossólido da ETE Sarapuí (Tabela 1), decorrente provavelmente da diferença nos processos de tratamento do esgoto e do lodo entre as duas ETEs. De acordo com Carvalho et al. (2015) biossólidos oriundos de secagem térmica, como da ETE Sarapui, tendem a preservar melhor os nutrientes e as frações biodegradáveis do carbono, enquanto no processo de secagem ao ar livre, como da ETE Ilha do Governador, pode ocorrer degradação da matéria orgânica mais disponível, bem como lixiviação de nutrientes.

Considerando que Luehea divaricata é espécie pioneira (Carvalho, 2008), que em geral são plantas relativamente bastantes responsivas a maiores quantidades de nutrientes no substrato, os resultados do presente 
trabalho indicam que biossólidos podem promover maior crescimento de espécies arbóreas de estágio sucessional inicial, como também observado por Alonso et al. (2018) para Ceiba speciosa St. Hil. e por Cabreira et al. (2017b) e Abreu et al. (2018) para produção de mudas de Schinus terebinthifolius Raddi em tubetes de $280 \mathrm{~cm}^{3}$. Estes dois últimos trabalhos demonstram que é possível produzir mudas de qualidade de aroeira pimenteira, pelos padrões indicados por Souza Junior e Brancalion (2016), usando apenas biossólido da ETE Ilha do Governador como substrato, e o mesmo para paineira por Alonso et al. (2018). Abreu et al. (2018) observaram, também que as mudas de aroeira pimenteira produzidas com biossólido apresentaram características de crescimento significativamente superiores as produzidas em mesmo substrato comercial deste trabalho. Ao adicionar 5, 10, 20 e 40 gramas de monoamônio fosfato parceladas em três vezes ao substrato, os autores observaram que as mudas produzidas com 40 gramas do adubo apresentaram crescimento semelhantes as produzidas apenas com o biossólido. Estes resultados indicam que o uso de biossólido como substrato pode reduzir ou suprimir a necessidade de fertilização para produção das mudas arbóreas de ocorrência na Mata Atlântica.

Segundo Souza Júnior e Brancalion (2016), mudas de Luehea divaricata, produzidas em tubetes de $290 \mathrm{~cm}^{3}$, semelhantes deste trabalho, estão em condições de serem plantadas em campo, de 3 a 4 meses após a repicagem, com altura de 20 a $40 \mathrm{~cm}$ e diâmetro do colo $>3 \mathrm{~mm}$, desde que devidamente rustificadas. Assim, aos 105 dias após a repicagem nos tubetes, verifica-se pela Tabela 3 , que as mudas produzidas com ambos biossólidos estariam aptas e as de substrato comercial ainda devem ficar no viveiro. Observa-se também pela Figura 1 que aos 75 dias após a repicagem, as mudas produzidas com biossólido procedente da ETE Sarapuí já atingiram esta altura mínima, indicando que o uso deste substrato diminui o tempo de produção das mudas e, consequentemente, os custos de produção. As mudas produzidas com o substrato comercial não atingiram este valor mínimo, no final de 105 dias após repicagem (Tabela 3), indicando, teoricamente, não estarem aptas para plantio de campo. Pela equação da Figura 1, mantendo o ritmo de crescimento no período estudado (até 105 dias), as plantas de açoita-cavalo atingiriam a altura mínima aos 7 meses após a repicagem.

Observando os dados apresentados na Tabela 1, verifica-se que o biossólido de Sarapuí apresentou maiores teores de nutrientes, em comparação com o da Ilha do Governador. Considerando a importância do $\mathrm{N}$ para o crescimento inicial das plantas, Abreu et al. (2071b) relataram o alto teor desse elemento nos biossólidos como uma das principais justificativas para o maior crescimento de mudas florestais produzidas em substratos a base desse material. Quanto ao P, Ceconi et al. (2006) mencionam que esse nutriente garante um arranque vigoroso das plantas estimulando o crescimento radicular, e que as mudas de Luehea divaricata cultivadas em vasos com em Argissolo Vermelho Amarelo responderam a adubação fosfatada, indicando ser espécie com certa exigência neste nutriente.

Avaliando substratos para produção de mudas da espécie arbórea Lafoensia pacari St. Hil., Abreu et al. (2017b) observaram que o biossólido de Sarapuí proporcionou maiores valores para as variáveis morfológicas analisadas quando comparado com o biossólido da Ilha do Governador e o biossólido da ETE Alegria, composto de lixo urbano e substrato comercial. Os autores atribuíram o maior crescimento das mudas com o biossólido Sarapui, devido à maior concentração de nutrientes, conforme também observado neste trabalho. De acordo com Davide et al. (2015), os macronutrientes são nutrientes altamente requeridos nos estádios iniciais de crescimento das mudas, com papel importante no arranque inicial do crescimento da parte aérea, o que justifica as maiores médias em altura e diâmetro nos tratamentos com maiores teores destes nutrientes.

O substrato comercial, pelos critérios de Gonçalves e Poggiani (2000), apresentou aparentemente melhores propriedades físicas que os biossólidos, tendo em vista sua menor condutividade elétrica e densidade aparente, níveis intermediários de capacidade de retenção de água e maior macroporosidade (Tabela 2). Em ambos biossólidos, verificou-se microporosidade mais elevada que a macroporosidade, o que pode dificultar o crescimento das raízes e a drenagem do substrato. Conforme observado por Guerrini e Trigueiro (2004), que testaram substratos com diferentes proporções de biossólido e casca de arroz carbonizada, maiores proporções de biossólidos ocasionam aumento da densidade e microporosidade do substrato. Os resultados de crescimento das mudas sugerem que as propriedades químicas do substrato foram mais determinantes que as físicas, reforçando a necessidade de gastos com fertilização para a produção de mudas no substrato comercial.

A condutividade elétrica (CE) observada para os biossólidos foi elevada, considerando que substratos acima de 1,0 dS.m ${ }^{-1}$ são considerados salinos e inadequados para produção de espécies florestais nativas (Gonçalves et al. 2000). Neste trabalho Luehea divaricata se mostrou tolerante quanto a esse parâmetro, assim como observado para outras três espécies florestais por HernándezApaolaza et al. (2005), onde substratos com biossólidos atingiram CE elevada (até 9,3 dS.m ${ }^{-1}$ ), o que não interferiu na produção de mudas. Os autores verificaram ainda que a CE reduziu para menos da metade ao final do período de produção das mudas, que teve duração de 12 meses, em consequência da lavagem do substrato pela irrigação durante a produção. No caso deste trabalho com açoitacavalo, que foram usados tubetes de $280 \mathrm{~cm}^{3}$ e que, em dias mais quentes foi irrigado até três vezes ao dia, provavelmente durante o processo de produção das mudas a condutividade elétrica dos substratos com biossólido foi diminuindo, não sendo fator limitante ao crescimento das mudas avaliadas aos 105 dias após repicagem .

Quanto ao $\mathrm{pH}$, o biossólido da ETE Sarapuí ap resentou valor elevado de 7,6, faixa de $\mathrm{pH}$ que pode dificultar a disponibilização de alguns nutrientes (Gonçalves e Poggiani, 1996). Tal fato não influenciou na produção de mudas da espécie avaliada, tendo em vista que nesse substrato foi observado o maior crescimento das mudas.

Para a maioria dos parâmetros morfológicos avaliados, o biossólido de ambas as ETEs proporcionaram crescimento superior das mudas de $L$. divaricata em relação àquelas produzidas com o substrato comercial (Tabela 3). Comparando os resultados de altura e diâmetro observados no presente trabalho, que são duas variáveis não destrutivas e de fácil determinação, com aqueles relatados para Luehea divaricata em diferentes substratos por Grutka et al. (2012) e Felker et al. (2015) verificou-se que as mudas produzidas no presente trabalho, em ambos os biossólidos, tiveram maior crescimento que nos demais estudos. As mudas do substrato comercial demonstraram as menores médias para todas as características avaliadas, o que pode ser explicado pela não realização de fertilizações de base e cobertura, necessárias quando se 
utiliza esse tipo de substrato. Resultado semelhante foi observado por Abreu et al. (2018), na produção de mudas de Schinus terebenthifolius em substratos, sendo os piores resultados verificados em uma formulação comercial e na ausência de fertilização complementar.

Para a MSPA (Tabela 2), os valores médios do biossólido de ambas as ETEs não diferiram estaticamente entre si. Em relação à MSR, Gomes et al. (2002) afirmam que essa característica pode ser utilizada para estimar a sobrevivência inicial da muda no campo. Dessa forma, as mudas produzidas com o biossólido da ETE Sarapuí teriam maior potencial de sobreviver após o plantio em campo. Os altos valores de MSR observados para o biossólido da ETE Sarapuí estão provavelmente relacionados ao maior teor de $\mathrm{P}$ desse material, tendo em vista a importância desse nutriente para o crescimento radicular (Ceconi et al. 2006). Altas proporções de biossólido no substrato tendem a proporcionar aumento na biomassa produzida pelas mudas em viveiro, conforme observado por Bortolini et al. (2017) para Cedrela fissilis e Anadenathera macrocarpa, onde substratos com proporções de $25 \%$ e $50 \%$ de biossólido proporcionaram aumento na MSPA, MSR e MST das espécies estudadas. Alonso et al. (2018) também observaram que a maior proporção de biossólido (100\%) produziu mudas de Ceiba speciosa com maior biomassa da parte aérea e de raízes do que 25 e $50 \%$ de biossólido no substrato, em tubetes de $280 \mathrm{~cm}^{3}$.

A relação massa de matéria seca da parte aérea / sistema radicular (PMSA/PMR) indica que as mudas de Luehea divaricata produzidas com biossólido da Ilha do Governador produziram proporcionalmente mais parte aérea do que raízes (Tabela 3). Juntamente com os dados de área foliar, variável relacionada à capacidade fotossintética da planta, os valores indicam que, caso as mudas produzidas com biossólido da ETE Ilha do Governador forem plantadas em ambientes que nos primeiros meses após o plantio sofrerem déficit hídrico no solo, há risco de baixa sobrevivência no campo.

Quanto ao índice de qualidade de Dickson (IQD), Davide et al. (2015) mencionam, que para uma mesma espécie, maiores valores podem indicar, teoricamente, mudas de melhor qualidade. Assim, as mudas de açoitacavalo produzidas com o biossólido da ETE Sarapuí, comparativamente entre os tratamentos, apresentam melhor qualidade e as de substrato comercial as de pior qualidade. Resultados semelhantes ao deste trabalho, foram obtidos por Cabreira et al. (2017a) que observaram maior valor de IQD para mudas de espécies arbóreas produzidas com substrato com maior proporção $(80 \%) \mathrm{de}$ biossólido e por Alonso et al. (2018) para mudas de Ceiba speciosa produzidas com $75 \%$ e $100 \%$ de biossólido na composição do substrato.

Normalmente não se produz mudas florestais em substrato comercial sem fertilização de base e cobertura, justificando o resultado inferior nesse tratamento. $\mathrm{O}$ resultado observado para o crescimento e qualidade das mudas produzidas com os biossólidos reforça a possibilidade de produzir mudas eliminando ou reduzindo fertilizações no viveiro. No entanto, para correta comparação dos substratos quanto ao seu desempenho e os reflexos de suas características físicas na produção de mudas é sugerida a comparação com o substrato comercial devidamente fertilizado, possibilitando inclusive a quantificação da redução dos gastos que a aplicação de biossólido pode promover na fertilização. Também é importante fase de campo, avaliando a taxa de sobrevivência e o crescimento até 6 meses após o plantio.

\section{Conclusões}

Os biossólidos de ambas ETEs se mostraram superiores ao substrato comercial, proporcionando mudas com maior crescimento e qualidade, tendo potencial e podendo ser indicados para produção de mudas de Luehea divaricata em tubetes de $280 \mathrm{~cm}^{3}$.

Considerando as características da espécie avaliada e os resultados observados, para produção de mudas de espécies pioneiras, como Luehea divaricata, é preferível à utilização do biossólido seco termicamente da ETE Sarapuí como substrato.

\section{Agradecimentos}

À Companhia Estadual de Águas e Esgotos (CEDAE) pela doação dos materiais e ao Conselho Nacional de Pesquisa Científica (CNPq) pela bolsa de Iniciação Científica.

\section{Referências}

Abreu AHM, Leles PSS, Alonso JM, Abel ELS, Oliveira RR (2017) Characterization of sewage sludge generated in Rio de Janeiro, Brazil, and perspectives for agricultural recycling, Semina: Ciências Agrárias, 38(4): 2433-2448, 2017a.

doi: https://doi.org/10.5433/16790359.2017v38n4Sup11p2433

Abreu AHM, Marzola LB, Melo LA, Leles PSS, Abel ELS, Alonso JM (2017) Urban solid waste in the production of Lafoensia pacari seedlings. Revista Brasileira de Engenharia Agrícola e Ambiental, 21(2): 83-87. doi: https://doi.org/10.1590/18071929/agriambi.v21n2p83-87

Abreu AHM, Oliveira, RR, Abel, ELS, Lima Filho, P, Leles, PSS. (2018) Biossólido e substrato comercial na produção de mudas de Schinus terebinthifolia. Pesquisa Florestal Brasileira, 38(4): 1-10. doi: 10.4336/2018.pfb.38e201501066

Alonso, JM, Abreu, AHM, Melo, LA, Leles, PSS, Cabreira, GV (2018) Biosolids as substrate for the production of Ceiba speciosa seedlings. Cerne, v. 24, n. 4, p. 420-429, 2018. doi 101590/010477021824042568.

Bortolini J, Tessaro D, Gonçalves MS, Oro SR (2017) Lodo de esgoto e cama de aviário como componente de substratos para a produção de mudas de Cedrela fissilis e Anadenanthera macrocarpa (Benth). Brenan. Scientia Agrária, 18(4): 121-128.

Brasil (2016) Ministério do Meio Ambiente. Conselho Nacional do Meio Ambiente. Resolução - CONAMA. Resolução n ${ }^{\circ} 375 / 2006$. Define critérios e procedimentos para o uso agrícola de lodos de esgoto gerados em estações de tratamento de esgoto sanitário e seus produtos derivados. Diário Oficial da República Federativa do Brasil, Brasília, (167): 141-146.

Cabreira GV, Leles PSS, Alonso JM, Abreu AHM, Lopes NF, Santos GR (2017a) Biossólido como componente de substrato para produção de mudas florestais. Floresta, 47(2): 165-176. doi: 10.5380/rf.v47i1.44291

Cabreira GV, Leles PSS, Araújo EJG, Silva EV, Lisboa AC, Lopes NL (2017b) Produção de mudas de Schinus terebinthifolius utilizando biossólido como substrato em diferentes recipientes e fertilizantes. Scientia Agraria, 18(2): $30-42$ 
Carvalho PER. Espécies arbóreas brasileiras: volume I. Colombo: Embrapa Florestas, 2008. 1039p.

Carvalho CS, Ribeirinho VS, Andrade CA, Grutzmacher P, Pires AMM (2015) Composição Química da Matéria Orgânica de Lodos de Esgoto. Revista Brasileira de Ciências Agrárias, 10(3): 413-419. doi: http://dx.doi.org/10.5039/agraria.v10i3a5174

Ceconi DS, Poletto I, Brun EJ, Lovato T (2006) Crescimento de mudas de açoita-cavalo (Luehea divaricata Mart.) sob influência da adubação fosfatada. Cerne, 12:(3):292-299.

Christodoulou A, Stamatelatou K (2016) Overview of legislation on sewage sludge management in developed countries worldwide. Water Science and Technology, 73:(3):453 - 462. doi: 10.2166/wst.2015.521.

Davide, AC, Melo, LA, Teixeira, NJP, Prado, NJ, Fiorine, RA, Carvalho, RP (2015) Fatores que afetam a qualidade de mudas destinadas aos projetos de restauração de ecossistemas florestais. In: Davide, AC, Botelho, SA (ed.). Fundamentos e métodos de restauração de ecossistemas florestais: 25 anos de experiências em matas ciliares. Lavras : UFLA, p. $181-274$

Dickson A, Leaf A, Hosner JF (1960) Quality appraisal of white spruce and white pine seedling stock in nurseries. Forestry chronicle 36:10-13.

Felker RM, Aimi SC, Stefanello MM, Piazza EM, Jung PH (2015) Crescimento de mudas de açoita-cavalo (Luehea divaricata Mart.) sob influência de diferentes substratos e recipientes, em viveiro. Enciclopédia biosfera, 11(22): 810.

doi: http://dx.doi.org/10.18677/Enciclopedia_Biosfera_2015_ 120

Firmino,MH (2014). Substratos: composição, caracterização e método de análise. Guaíba: Agrolivros, $111 \mathrm{p}$.

Gomes JM, Couto L, Leite HG, Xavier A, Garcia SLR (2002) Parâmetros morfológicos na avaliação da qualidade de mudas de Eucalyptus grandis. Revista Árvore, 26(6): 655-664. doi: http://dx.doi.org/10.1590/S0100 67622002000600002

Gonçalves JLM, Poggiani F (2000) Produção de mudas de espécies nativas: substrato, nutrição, sombreamento e fertilização. In: Gonçalves, JLM. Benedetti, V. (Eds.) Nutrição e fertilização florestal IPEF p. 80-102.

Grutka THH, Frigo MS, Frigo EP, Tessaro D (2012) Efeito de diferentes proporções de adubação orgânica sobre o desenvolvimento de mudas de açoita-cavalo (Luehea divaricata). Engenharia Ambiental - Espírito Santo do Pinhal, 9:(1): 17-25

Guerrini IA, Trigueiro RM (2004) Atributos físicos e químicos de substratos compostos por biossólidos e casca de arroz carbonizada. Revista Brasileira de Ciência do Solo, 28(1): 1069-1076

Hernández-Apaolaza L, Gascó AM, Gascó JM, Guerrero F (2005) Reuse of waste materials as growing media for ornamental plants. Bioresource Technology, 96(1): 125131.

José AC, Davide AC, Oliveira SL (2005) Produção de mudas de aroeira (Schinus terebinthifolius Raddi) para recuperação de áreas degradadas pela mineração de bauxita. Cerne 11(2): 187-196 doi: http://www.redaly c.org/articulo.oa?id=74411209

Lima Filho, P, Leles, PSS, Abreu, AHM, Silva, EV, Fonseca, AC. (2019). Produção de mudas de Ceiba speciosa em diferentes volumes de tubetes utilizando o biossólido como substrato. Ciência Florestal, 29 (1): 27 39. doi : https://doi.org/10.5902/1980509819340

Kominko H, Gorazda K, Wzorek, Z (2017) The possibility of Organo-Mineral fertilizer production from sewage sludge. Waste and Biomass Valorization, 1(1):1-11. doi: 10.1007/s12649-016-9805-9.

Nobrega MAS, Pontes MS, Santiago EF (2017) Incorporação do lodo de esgoto na composição de substrato para produção de mudas nativas. Acta Biomedica $\begin{array}{llll}\text { Brasiliensia } & 8(1): & 43-55 . & \text { doi: }\end{array}$ http://dx.doi.org/10.18571/acbm.121

Pereira RD, Murashita EM, Fluminhan JRA (2013) Reciclagem agrícola de biossólidos: Aspectos ambientais e aceitação pública. Colloquium humanaru, 10(2):90-101. doi: 10.2166/wst.2015.521

SNIS - Sistema Nacional de Informações sobre Saneamento: Diagnóstico dos Serviços de Água e Esgotos - 2014, SNSA/MCIDADES, Ministério das Cidades, Secretaria Nacional de Saneamento Ambiental, Brasília, 2016.

Scheer MB, Carneiro C, Bressan AO, Santos KG (2012) Crescimento e nutrição de mudas de Lafoensia pacari com lodo de esgoto. Floresta e Ambiente, 19(1):55-65. doi: http://dx.doi.org/10.4322/floram.2012.007

Souza Junior, CN, Brancalion, PHS. (2016). Sementes e mudas: guia para propagação de árvores brasileiras. São Paulo: Oficina de textos, 463p. 